\title{
METROLOGICAL BEHAVIOUR OF BULK WATER METERS UNDER DIVERSE INSTALLATION CONFIGURATIONS
}

\author{
Carmen V. Palau' ${ }^{*}$, Iban B. Peralta ${ }^{2}$, Juan Manzano², Benito M. de Azevedo ${ }^{3}$, \\ Guilherme V. do Bomfim ${ }^{3}$
}

${ }^{1 *}$ Corresponding author. Universitat Politècnica de València/Valencia, Spain. E-mail: virpaes@agf.upv.es

\author{
KEYWORDS \\ hydrometry, water \\ consumption, \\ pressurised irrigation.
}

\begin{abstract}
As the correct measurement is an essential part of water management, this study describes the metrological behaviour of a range of bulk water meters under different installation configurations. The meters analysed included the horizontal and vertical Woltman, singlejet, tangential and proportional. Configurations included straight pipe lengths; gate and butterfly valves at different degrees of closure, rotations and distances from the meter; meter with volumetric and reducing valves; reverse installation; and meter rotated $90^{\circ}$ from the horizontal setting. The metrological behaviour under different flow conditions was analysed by comparison with electromagnetic and volumetric meters (ISO-4064). The horizontal Woltman showed no permissible errors with reverse installation; gate valve closed $75 \%$ and placed alongside the meter; and with butterfly valve closed $30^{\circ}$, non-rotated, and rotated right or left. The vertical Woltman gave no permissible errors with reverse installation. The single-jet meter did not show any errors above the permitted limit. The tangential meter had no permissible errors with reverse installation and in almost all configurations with gate and butterfly valves. The proportional meter showed no permissible errors with a gate valve at any degree of closure.
\end{abstract}

\section{INTRODUCTION}

Good quality water is an indispensable natural resource for the development of countries. At present, there is increasing worry over its conservation since demand has increased while the supply is decreasing (Constantine et al., 2017; Grafton, 2017; Otaki et al., 2017). The solution to this situation could be either to increase the water supply or to reduce its consumption. In either case, it is necessary to obtain precise information on how much water enters the system and how much is consumed, which can be achieved by micro and macro water measurements (Beardsley, 2017).

Bulk measuring systems deal with large volumes of water and are used in pumping stations, distribution networks, hydraulic sectors and irrigation heads. The frequently used technologies include flow meters, such as Woltman, volumetric valve, single-jet, tangential and proportional (Barana et al., 2014; Betta et al., 2002; Daneshnia et al., 2016; Pardo et al., 2013; Wesström et al., 2014; Zhen \& Tao, 2008).

The installation and operation configuration of bulk meters and the accompanying hydraulic elements are some of the factors that can distort the velocity profile and cause important measurement errors (Arregui et al., 2006; Fontanazza et al., 2013). Therefore, experimental evaluation of the optimal installation and operational configurations of these apparatus is fundamental for proper control and management of water in pressure networks.

Arregui et al. (2007) summed up the main operating characteristics and the influence of distorted velocity profiles on the technologies mentioned above. Briefly, horizontal and vertical Woltman meters measure the axial flow over a rotor. In those with a horizontal axis, the flow is in the same direction as the rotor axis, and so distorted profiles have a greater effect on their metrology than the vertical-axis meter. In vertical-axis meters, the flow is perpendicular to the rotor axis so that velocity profiles suffer internal changes of direction inside the meter, as far as the rotor and any elements installed upstream of the meter have less effect on its precision than the horizontal-axis meter. Volumetric valves are a variation of the vertical-axis Woltman meters with an added valve to control either flow or pressure or both together.

\footnotetext{
${ }^{2}$ Universitat Politècnica de València/ Valencia, Spain.

${ }^{3}$ Universidade Federal do Ceará/ Fortaleza - CE, Brazil. 
Single-jet meters measure water consumption, by counting the turbine revolutions when the water impinges on a single point on its periphery. As the inlet nozzle and the turbine chamber have slightly converging shapes, any distorted profiles can be corrected without seriously affecting their precision.

The operation of tangential meters is based on the movement of a turbine fitted to the upper surface of a pipe. The precision varies according to how the speed profile reaches the turbine, and serious errors are not uncommon.

Proportional meters incorporate two parallel circuits; the main flow passes through the first while the second has a secondary flow that is measured by a single- or multiplejet meter. By measuring one flow, the total flow through the meter can be calculated from the resistance characteristics of both circuits. Distorted velocity profiles at the inlet of the secondary circuit can affect their precision.
Research on the metrology of bulk water meters can be considered essential since the available studies in the literature do not adequately cover this topic. Therefore, this study aims to evaluate the influence of diverse installation and operation configurations on the error curve of bulk water meters and to propose adequate configurations for minimising measurement errors to acceptable values.

\section{MATERIAL AND METHODS}

The metrological behaviour of bulk water meters of diverse installation configurations was studied in an ITA Sustainable Urban Water Management test bench at the Universitat Politècnica de València, Valencia, Spain (Figure 1).

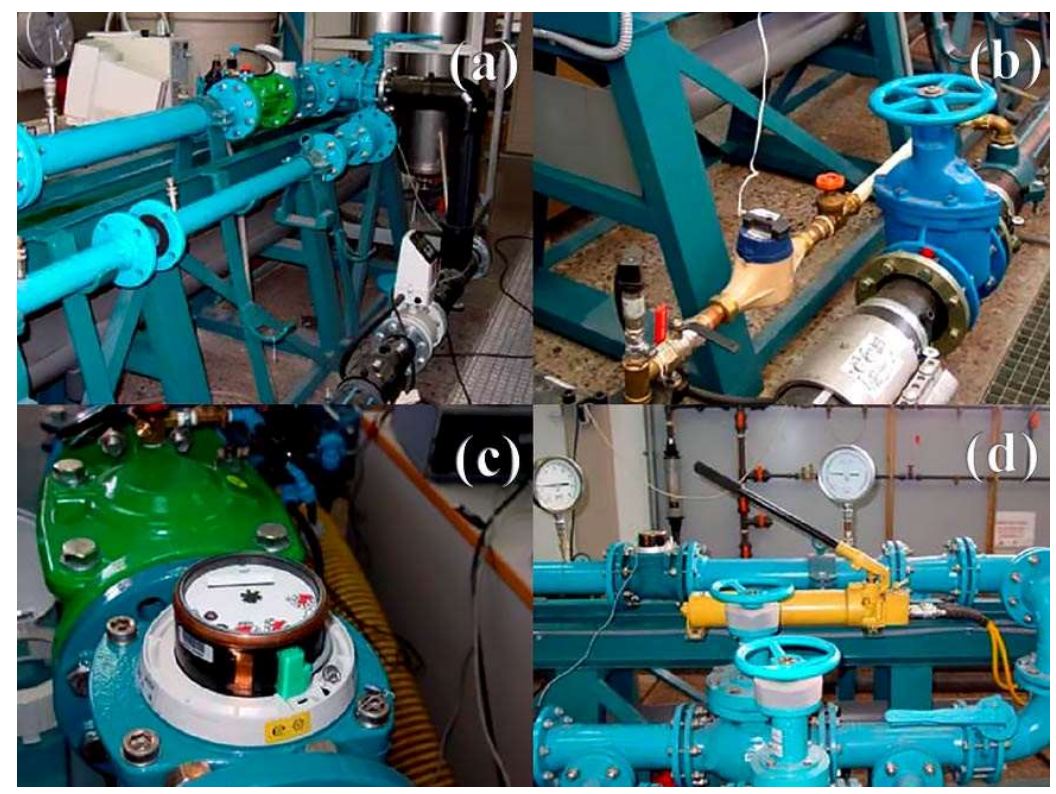

FIGURE 1. View of test bench and equipment for metrological evaluation of bulk water meters: electromagnetic flow meter with meter under test (a); bypass circuit for low-flows with a precision volumetric meter (b); Reed-type pulse emitter (c); flow regulating valves $(\mathrm{d})$.

The principal elements used on the test bench included: water meters, $80 \mathrm{~mm}$ electromagnetic flow meter with a reading precision of $\pm 0.5 \%$; volumetric meter with a reading precision from \pm 0.5 to $\pm 2 \% ; 100 \mathrm{~mm}$ gate and butterfly valves; 50 and $100 \mathrm{~mm}$ seat valves; $80 \mathrm{~mm}$ reducing valve; 0-1.6 $\mathrm{MPa}$ range pressure transducer with precision of $\pm 0.28 \%$ on the full scale; Bourdon-type manometers of up to $1.6 \mathrm{MPa}$ with precision of $\pm 0.5 \%$ on the full scale; variable-frequency drive; two $18.5 \mathrm{~kW}$ pumps installed in parallel; metallic tubing of 50, 80 and $100 \mathrm{~mm}$; personal computer; data acquisition system with Labview ${ }^{\odot}$ software. Table 1 lists the water meters tested and their principal metrological characteristics.

TABLE 1. Metrological description of tested water meters.

\begin{tabular}{cccccccccc}
\hline \multirow{2}{*}{ Technology } & \multirow{2}{*}{ MC } & \multirow{2}{*}{$\mathrm{DN}(\mathrm{mm})$} & \multicolumn{5}{c}{ Flow $\left(\mathrm{m}^{3} \mathrm{~h}^{-1}\right)$} \\
\cline { 4 - 9 } & & & Minimum & Transition & Overload & Permanent & Starting & MHL $(\mathrm{MPa})$ \\
\hline Horizontal Woltman & $\mathrm{B}$ & 80 & 1.8 & 12 & 120 & 60 & 0.3 & 0.06 \\
Vertical Woltman & $\mathrm{B}$ & 80 & 1.2 & 8 & 80 & 40 & 0.1 & 0.06 \\
Volumetric valve $^{1}$ & $\mathrm{~A}$ & 100 & 4.8 & 18 & 180 & 110 & - & - \\
Single-jet & $\mathrm{C}$ & 80 & 0.18 & 0.45 & 60 & 30 & - & - \\
Tangential & $\mathrm{A}$ & 80 & 3.2 & 12 & 80 & 40 & -145 \\
Proportional $^{2}$ & - & 80 & 4.8 & - & 120 & - & 1.8 & 0.044 \\
\hline
\end{tabular}

MC: metrological class; DN: nominal diameter; MHL: Maximum head loss; ${ }^{1}$ volumetric valve is vertical-axis Woltman with a control valve activated by a diaphragm with auxiliary closure valve for dosages; ${ }^{2} \pm 5 \%$ accurate proportional technology is not metrologically approved. 
The meter and hydraulic accessories' installation and management configurations were those commonly used in pumping stations, distribution networks, hydraulic sectors and irrigation heads (Table 2).

TABLE 2. Installation and operating configurations of water meters and accessories.

Technology Configuration

\begin{tabular}{|c|c|}
\hline Horizontal Woltman & $\begin{array}{l}\text { Gate valve at } 0 \mathrm{D} \text { and } 3 \mathrm{D} \text { from meter, working open, } 25,50 \text { and } 75 \% \text { closed; butterfly valve at } 3 \mathrm{D} \\
\text { from meter, working open, } 30^{\circ} \text { closed, and } 30^{\circ} \text { closed rotated right or left; pressure reducing valve } \\
\text { at } 0 \mathrm{D} \text { from meter; meter installed against flow. }\end{array}$ \\
\hline Vertical Woltman & $\begin{array}{l}\text { Gate valve at } 0 \mathrm{D} \text { from meter, working } 50 \text { and } 75 \% \text { closed; gate valve at } 3 \mathrm{D} \text { from meter, working } \\
\text { open, } 25,50 \text { and } 75 \% \text { closed; meter with volumetric valve; meter installed against flow. }\end{array}$ \\
\hline Single-jet & Gate valve at $0 \mathrm{D}$ and $3 \mathrm{D}$ from meter, working 50 and $75 \%$ closed. \\
\hline Tangential & $\begin{array}{l}\text { Gate valve at } 0 \mathrm{D} \text { from meter, working open, } 25,50 \text { and } 75 \% \text { closed; gate valve at } 3 \mathrm{D} \text { from meter, } \\
\text { working } 50 \text { and } 75 \% \text { closed; butterfly valve at } 3 \mathrm{D} \text { from meter, working open, open rotated left, } 30^{\circ} \\
\text { closed and } 30^{\circ} \text { closed rotated right or left; butterfly valve at } 6 \mathrm{D} \text { from meter, working } 30^{\circ} \text { closed; } \\
\text { pressure reducing valve at } 0 \mathrm{D} \text { from meter; meter installed against flow and } 90^{\circ} \text { rotated from the } \\
\text { horizontal. }\end{array}$ \\
\hline Proportional & $\begin{array}{l}\text { Gate valve at } 0 \mathrm{D} \text { and } 3 \mathrm{D} \text { from meter, working open, } 25,50 \text { and } 75 \% \text { closed; butterfly valve at } 3 \mathrm{D} \\
\text { from meter, working } 30 \text { and } 40^{\circ} \text { closed. }\end{array}$ \\
\hline
\end{tabular}

$\mathrm{D}$ : distance from meter equivalent to pipe diameter; gate and butterfly valves were installed upstream of the meter while reducing valves were installed downstream, respectively.

The method used to study the meters was based on ISO 4064-2 (2014). The meters were compared with more accurate equipment (an electromagnetic flow meter and precision volumetric meter).

Tests commenced with the lowest flows, and these were gradually increased, as recommended in the technical specifications accompanying each device. Flow data from both the meters studied and the precision devices were uploaded to a data acquisition system programmed with Labview $^{\mathcal{C}}$ software.

The measurement error (error of indication) was estimated according to [eq. (1)], comparing the flow rate measured by bulk meters (indicated flow rate) with the flow rate measured by volumetric or electromagnetic meters (actual flow rate), according to the range of flows involved in the test (ISO 4064-2, 2014).

Measurement error $(\%)=\frac{\text { Indicated flow rate }\left(\mathrm{L} \mathrm{h}^{-1}\right)-\text { Actual flow rate }\left(\mathrm{L} \mathrm{h}^{-1}\right)}{\text { Indicated flow rate }\left(\mathrm{L} \mathrm{h}^{-1}\right)} \times 100$
A graphical representation of the relative error evolution with real flow rate measured by using the reference instrument (error curve) was drawn for each bulk water meter. The behaviour of all devices in different flow conditions was compared with the metrological curve obtained on straight pipe lengths with no flow distortion.

ISO 4064-1 (2014) requires the error curves to be within $\pm 5 \%$ between the minimum flow rate and transitional flow rate, and $\pm 2 \%$ between the transitional flow rate and overload (maximum) flow rate established for Class B Metrology (Metrological Class 2). Instruments with outdated metrology Class A, vary the flow rate limits, having minimum, transitional and overload flow rates higher than in Class B.

\section{RESULTS AND DISCUSSION}

\section{Woltman meters}

The metrological tests on the horizontal axis Woltman meter showed that the configurations evaluated affected the flow measurements (Figure 2). 

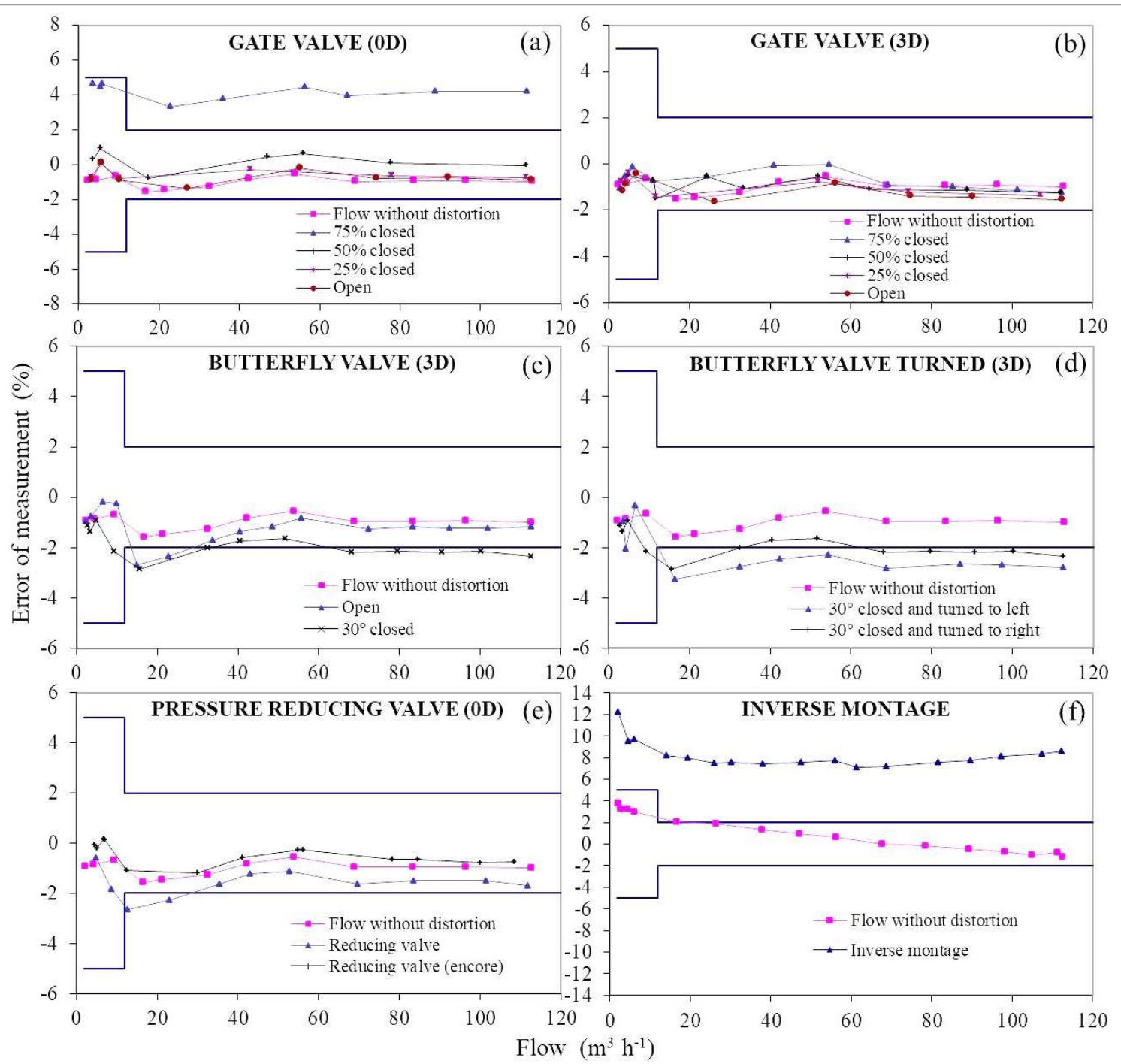

FIGURE 2. Measurement error of horizontal-axis Woltman meter with upstream gate valve configurations at 0D (a) and 3D (b); upstream butterfly valve closed to $30^{\circ}$ at $3 \mathrm{D}$ non-rotated (c) and rotated (d); downstream reducing valve at 0D (e); and inverted meter installation (f). D: distance of meter equal to diameter of pipe.

The open gate valve at $0 \mathrm{D}$ does not cause errors above an acceptable limit. However, as the valve is closed, the error increases to positive values and exceeds the limits established for Class B Metrology (Metrological Class 2; ISO 4064-1, 2014) when closed 75\% (Figure 2a). The error is caused by the gate valve distorting the velocity profiles and abruptly increasing their magnitude in the lower section of the pipe, thereby creating low-speed recirculation zones in the upper section (Augusto \& Cristianini, 2012). The high speeds in the lower pipe section increase torque, and thus, the rotor speed, to bring about positive errors. When the profile reaching the rotor vanes is less deformed (i.e., at 3D), measurements are less affected (Figure 2b), indicating that $3 \mathrm{D}$ may be a sufficient distance to moderate distortion and achieve acceptable accuracy.

An open butterfly valve at 3D has no marked effect on the accuracy of the meter; small sub-metering errors were only noted at $30^{\circ}$ of closure (Figure $2 \mathrm{c}$ ). In this case, when the valve is open, the flow is reduced while speed increases with no substantial distortions (Corbera et al., 2016), and asymmetric flow distortions may occur on both sides of the pipe when partially closed (Dawy et al., 2013). With the butterfly valve $30^{\circ}$ closed and turned mainly to the left, the flow generated directly impinges on the valve disk at high speed, changes the angle of incidence on the turbine, reduces speed and causes sub-metering errors slightly more than Class B metrology limits (Figure 2d). In this particular case, the valve must be at more than $3 \mathrm{D}$ from the meter, to generate flow distortion and keep the errors below Class $\mathrm{B}$ metrology limits.

Although a reducing valve beside the meter has no substantial influence on measurement, there is a slight tendency to both negative and positive errors (Figure 2e). Flow distortions caused by this type of valve are usually small on the upstream side of the pipe, as has been shown in a numerical simulation (Wei et al., 2015).

Reverse installation causes the largest sub-metering errors of around $-10 \%$ (Figure $2 \mathrm{f}$ ). This result originates because the model tested was not completely symmetrical, and the metrology regulation vane is only located upstream of the propeller in direct flow (Arregui et al., 2007), which means that a horizontal Woltman without a downstream non-return valve, may cause serious measurement errors. It is, therefore, necessary when acquiring this type of device, to either ensure a single flow direction or that the manufacturer specifies the errors in both directions.

The metrological tests on the vertical-axis Woltman show that this type is not particularly sensitive to distorted profiles (Figure 3). 


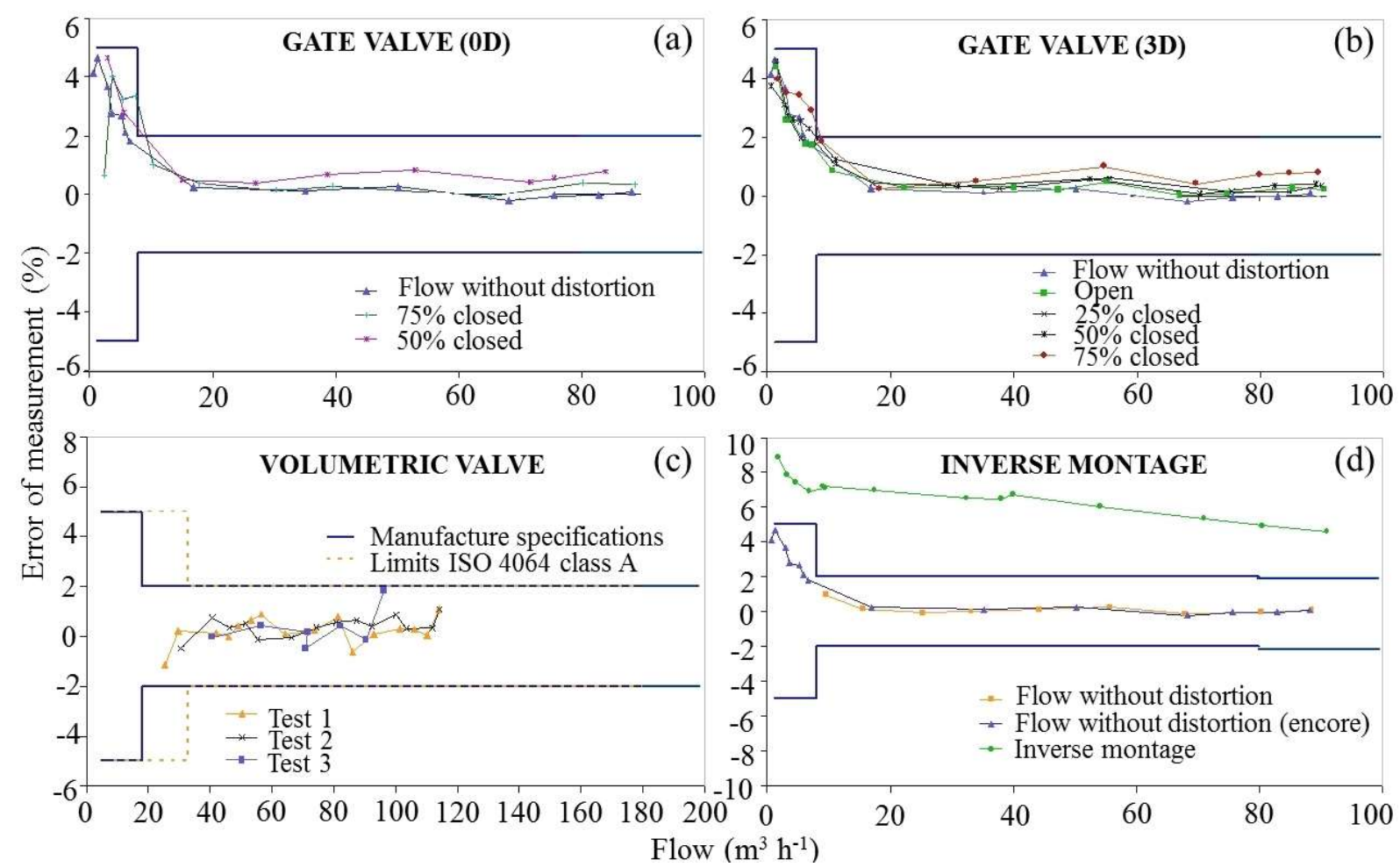

FIGURE 3. Measurement error of vertical-axis Woltman caused by different configurations of a gate valve at 0D (a) and 3D (b); by a volumetric valve (c); and by inverted meter installation (d). D: distance from meter equal to pipe diameter.

Installing a gate valve at $0 \mathrm{D}$ (Figure 3a) and 3D (Figure $3 \mathrm{~b}$ ) from this meter, has a practically irrelevant effect on its measurement error. This finding can be explained because the distorted speed profile does not directly impinge on the rotor but divides into different directions inside the meter. Moreover, the rotor axis, being perpendicular to the pipe axis, generates turbulence in the flow, which means that any other preceding alteration does not directly act on the turbine.

When the flow is limited by a volumetric valve this device's error curve is well within the Class A limits (Figure 3c). Only the reverse installation of a meter substantially affects flow measurements and causes errors of the order of $+6 \%$ (Figure 3d), due to the design of the rotor vanes and central pivot of the vertical Woltman, which alter the speed and angle of incidence of the flow in different directions. As in the case of the horizontal Woltman, when flow direction can be reversed, it is important to select a model guaranteed by the manufacturer to have equal errors in both flow directions (Arregui et al., 2007).

It is also important for both these Woltman types that the installation distances specified in the catalogue be satisfied. According to Arregui et al. (2007), these recommendations may vary expressively from one model to another and, also, among different manufacturers, even when flow stabilisers are used.

\section{Single-jet meter}

This meter obtained very favourable results, owing to its operating principle and construction, which make it almost insensitive to the velocity profiles generated by a gate valve (Figure 4).

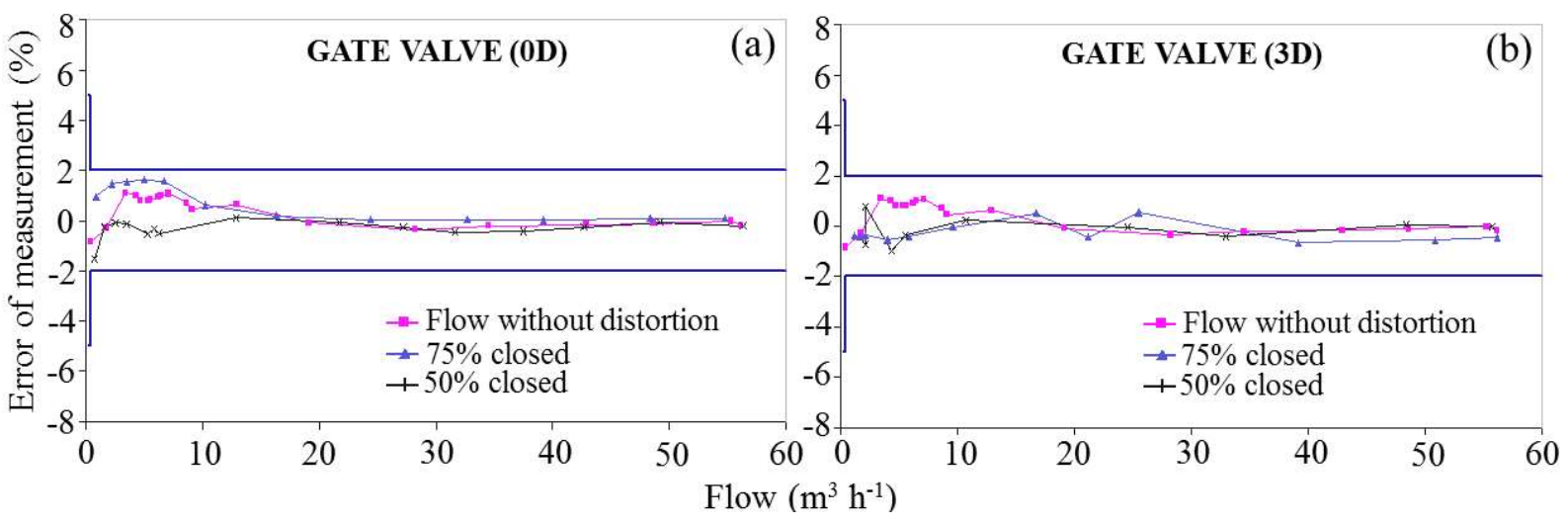

FIGURE 4. Measurement error of single-jet at different gate valve configurations, at 0D (a) and 3D (b). D: distance from meter equal to pipe diameter. 
It should be noted that at the most unfavourable configuration (gate valve $75 \%$ closed at $0 \mathrm{D}$ ), the device's behaviour is almost identical to that obtained with nondistorted flows (Figure 4a). In this case, it is logical to suppose that installing it at $3 \mathrm{D}$ upstream on a straight pipe will not achieve any further benefits (Figure $4 \mathrm{~b}$ ) since the inlet nozzle is slightly convergent and distorts the inlet velocity profiles, due to altered flow directions and lower pipe sections, so that prior distortions do not considerably affect the error curve (Arregui et al., 2007). The device's low sensitivity to flow distortions and its small space requirements are notable advantages (Silva et al., 2012).
When the meter was installed in the reverse direction, the rotor was not seen to move, so that the flow could not be measured (turbine stopped). Even though some models can operate in the reverse direction, this is not a recommended installation since there may be substantial sub-metering errors.

\section{Tangential meter}

The metrological tests show that this meter, influenced by water speed variations in the upper section of the pipe, is the most sensitive to flow distortions caused by hydraulic accessories (Figure 5).

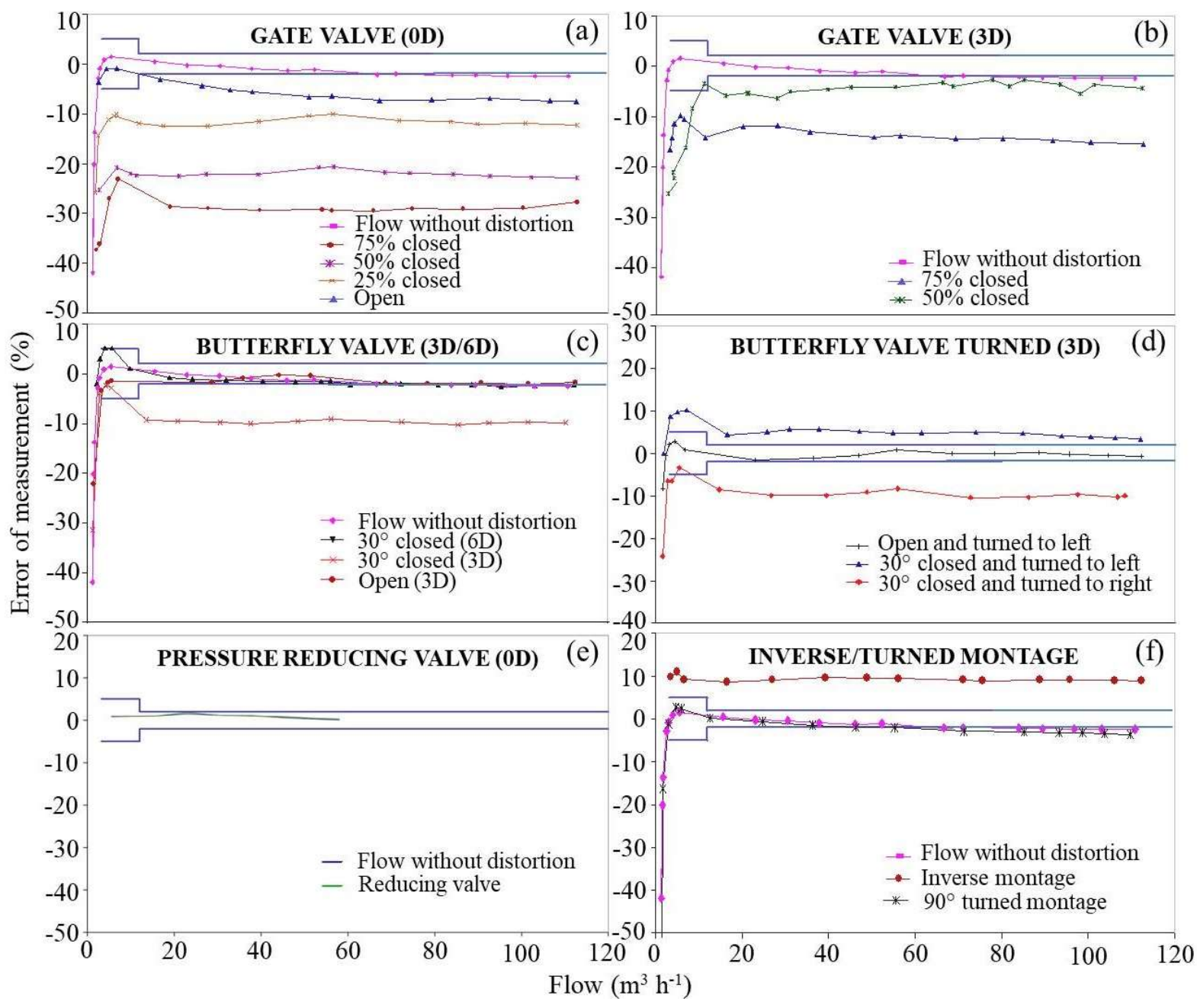

FIGURE 5. Measurement error of tangential meter at different upstream gate valve configurations at 0D (a) and 3D (b); of upstream, unturned butterfly valve (c) and turned (d); of downstream reducing valve (e); of reversed meter installations rotated $90^{\circ}$ from the horizontal (f). D: distance from meter equal to pipe diameter.

The gate valve greatly alters the velocity profiles in the upper pipe section (Augusto \& Cristianini, 2012), thereby producing serious measuring errors. At $0 \mathrm{D}$ from the meter and $75 \%$ closed, these speeds are quite low and generate reverse flows and sub-metering of up to $-30 \%$ of the actual volume (Figure 5a). A distance of 3D, in spite of being unsuitable, considerably reduces the error at $75 \%$ closure to approximately $15 \%$ (Figure 5b), which implies that the gate valve should be placed at more than $3 \mathrm{D}$ to achieve a suitable meter speed profile.

The open butterfly valve at $3 \mathrm{D}$ does not alter the error curve, but when closed to $30^{\circ}$, changes it to approximately $-10 \%$, which can be solved by lengthening the straight distance between the instrument and the valve to $6 \mathrm{D}$ (Figure $5 \mathrm{c}$ ). When this valve is closed to $30^{\circ}$ and rotated to the left, the speeds in the upper pipe cause submetering errors of around $+5 \%$, and when rotated to the right, the sub-metering errors are about $-10 \%$ (Figure $5 \mathrm{~d}$ ). This behaviour is due to the partially closed valve recirculating the flow in different zones at the sides of the pipe (Vakili-Tahami et al., 2012). When the valve is rotated, the distorted profiles reach the upper pipe section in different ways, causing over-metering and sub-metering errors, according to the direction of the rotation. 
The reducing valve causes very small measurement errors, close to those obtained in an installation of straight pipe lengths (Figure 5e), due to the valve being downstream of the meter and, thus, not considerably distorting the meter's inlet flow. In a numerical simulation, this type of valve has been shown not to cause important upstream distortions (Wei et al., 2015).

In the reverse installation, the device's errors are quite high, around $+10 \%$, showing that this configuration is not suitable since the downstream and upstream flow deflectors are not completely symmetrical (Arregui et al., 2007). When this meter is rotated $90^{\circ}$, the results are within the normal limits (Figure 5f), although Arregui et al. (2007) consider that this configuration should be avoided since it reduces the support of the turbine shaft and thereby, the sensitivity to low flows and their measurement with time, as well.

\section{Proportional meter}

The tests on the proportional meter indicate that only a gate valve causes important measurement errors (Figure 6).

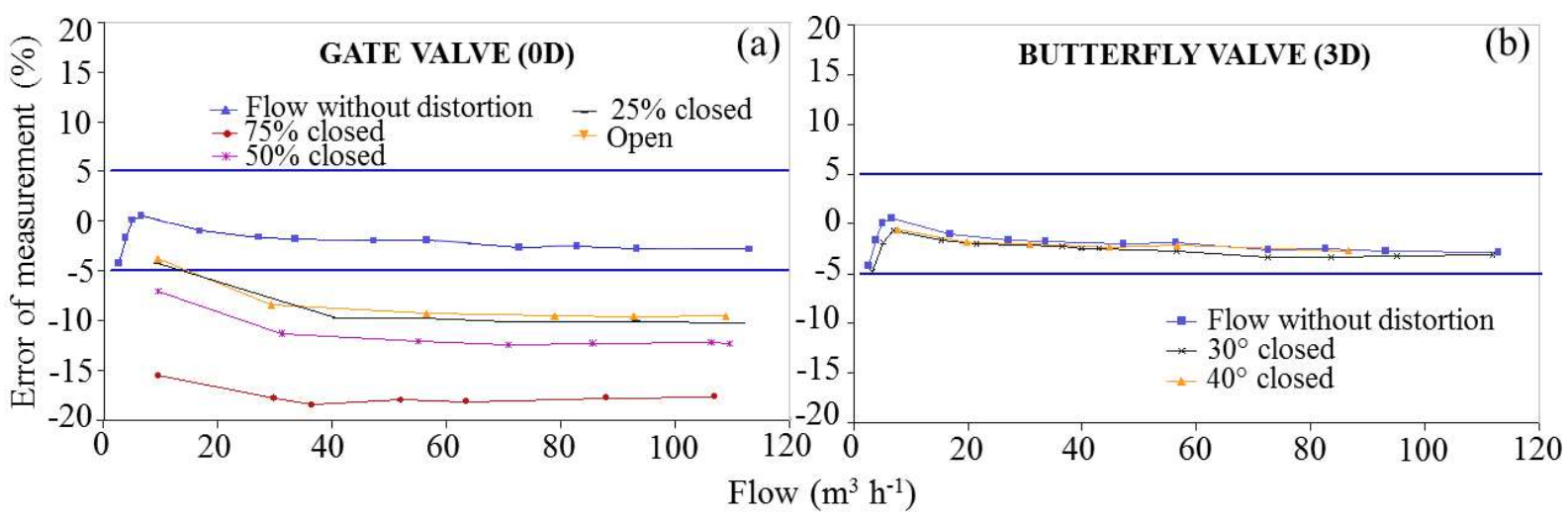

FIGURE 6. Measurement error of proportional meter at different upstream gate valve configurations at 0D (a); and upstream butterfly valve at $3 \mathrm{D}$ (b). D: distance from meter equal to pipe diameter.

The gate valve at $0 \mathrm{D}$, at any degree of closure, causes flow alterations with high speeds at the meter inlet and negative metering errors (Figure 6a), due to local variations in the resistance characteristics of the meter's secondary circuit at high inlet speeds, caused by the influence of the distorting element on the flow (Arregui et al., 2007).

The results of the gate valve at $3 \mathrm{D}$ were not conclusive, due to its filter being mistakenly fitted incorrectly, showing the extreme importance of this step since serious errors can be caused by changing the relationships between the characteristics of both circuits.

The butterfly valve at $3 \mathrm{D}$, at different degrees of closure (Figure 6b), does not noticeably alter the error curve.

\section{CONCLUSIONS}

The evaluation of the metrological behaviour of bulk water meters in diverse configurations and operations made it possible to define the configurations with the minimum acceptable metering errors.

In the horizontal Woltman meter, a gate valve open or $50 \%$ closed may be placed beside the meter, but at $75 \%$ should be at a distance of at least 3D. A butterfly valve open or $30^{\circ}$ closed should be at $3 \mathrm{D}$ from the meter, but if $30^{\circ}$ closed rotated to the left, the distance should be increased. A reducing valve may be used with no restrictions.

In the vertical Woltman meter, a gate valve can be installed at any distance and closed to $75 \%$ without causing serious errors. A volumetric valve used to limit the flow has no installation restrictions.

A single-jet meter beside a gate valve closed up to $75 \%$, can be installed at any distance.
In the tangential meter, a gate valve should be used at distances over 3D. An open butterfly valve can be at 3D from the meter, but if closed to $30^{\circ}$ and rotated, it should be at least $6 \mathrm{D}$. A downstream reducing valve can be installed without restrictions.

A butterfly valve may be placed at least 3D upstream on a straight pipe from a proportional meter, at closures between 30 and $40^{\circ}$. A gate valve should not be positioned beside the meter when closed to any degree.

All water meters should be installed in the direction of the water flow.

\section{REFERENCES}

Arregui FJ, Cabrera E, Cobacho R, García-Serra J (2006) Reducing apparent losses caused by meters inaccuracies. Water Practice and Technology 1(4). DOI: http://dx.doi.org/10.2166/wpt.2006.093

Arregui F, Cabrera Jr, E, Cobacho R (2007) Integrated Water Meter Management. London, IWA. 274p.

Augusto PED, Cristianini M (2012) Using computational fluid dynamics (CFD) for evaluation of fluid flow through a gate valve. International Journal of Food Engineering 8(4). DOI: http://dx.doi.org/10.1515/1556-3758.2207

Barana AC, Botelho VMB, Wiecheteck GK, Doll MMR, Simões DRS (2014) Rational use of water in a poultry slaughterhouse in the state of Paraná, Brazil: a case study. Engenharia Agrícola 34(1):171-178. DOI: http://dx.doi.org/10.1590/S0100-69162014000100018

Beardsley JC (2017) The use of water meters. Journal American Water Works Association 109(3):54-57. 
Betta V, Cascetta F, Palombo A (2002) Cold potable water measurement by means of a combination meter. Measurement 32(3):173-179. DOI: http://dx.doi.org/10.1016/S0263-2241(02)00017-9

Constantine K, Massoud M, Alameddine, I, El-Fadel M (2017) The role of the water tankers market in water stressed semi-arid urban areas: implications on water quality and economic burden. Journal of Environmental Management 188:85-94. DOI:

http://dx.doi.org/10.1016/j.jenvman.2016.11.065

Corbera S, Olazagoitia JL, Lozano JA (2016) Multiobjective global optimization of a butterfly valve using genetic algorithms. ISA Transactions 63:401-412. DOI: http://dx.doi.org/10.1016/j.isatra.2016.03.008

Daneshnia F, Amini A, Chaichi MR (2016) Berseem clover quality and basil essential oil yield in intercropping system under limited irrigation treatments with surfactant. Agricultural Water Management 164:331-339. DOI: http://dx.doi.org/10.1016/j.agwat.2015.10.036

Dawy A, Sharara A, Hassan A (2013) A numerical investigation of the incompressible flow through a butterfly valve using CFD. International Journal of Emerging Technology and Advanced Engineering 3(11):1-7.

Fontanazza CM, Notaro V, Puleo V, Freni G (2013) Effects of network pressure on water meter underregistration: an experimental analysis. Drinking Water Engineering and Science Discussions 6:119-149. DOI: http://dx.doi.org/10.5194/dwesd-6-119-2013

Grafton RQ (2017) Responding to the 'wicked problem' of water insecurity. Water Resources Management 31(10):3023-3041. DOI: http://dx.doi.org/10.1007/s11269017-1606-9

ISO 4064-1 - International Organization for Standardization (2014) Water meters for cold potable water and hot water -- Part 1: Metrological and technical requirements. Switzerland, ISO, 38p.
ISO 4064-2 - International Organization for Standardization (2014) Water meters for cold potable water -- Part 2: Test methods. Switzerland, ISO, 101p.

Otaki Y, Ueda K, Sakura O (2017) Effects of feedback about community water consumption on residential water conservation. Journal of Cleaner Production 143:719-730. DOI: http://dx.doi.org/10.1016/j.jclepro.2016.12.051

Pardo MA, Manzano Juarez J, Cabrera Marcet E, García Serra J (2013) Energy audit of irrigation networks.

Biosystems Engineering 115(1):89-101. DOI: http://dx.doi.org/10.1016/j.biosystemseng.2013.02.005

Silva DGM, Erazo JG, Cruz AMO (2012) Eficiencia en el consumo de agua de uso residencial. Revista Ingenierías Universidad de Medellín 11(21):23-38.

Vakili-Tahami F, Zehsaz M, Mohammadpour M, VakiliTahami A (2012) Analysis of the hydrodynamic torque effects on large size butterfly valves and comparing results with AWWA C504 standard recommendations. Journal of Mechanical Science and Technology 26(9):2799-2806. DOI: http://dx.doi.org/10.1007/s12206-012-0733-8

Wei L, Zhu G, Qian J, Fei Y, Jin Z (2015) Numerical simulation of flow-induced noise in high pressure reducing valve. PloS One 10(6):e0129050. DOI: http://dx.doi.org/10.1371/journal.pone.0129050

Wesström I, Joel A, Messing I (2014) Controlled drainage and subirrigation - A water management option to reduce non-point source pollution from agricultural land. Agriculture, Ecosystems \& Environment 198:74-82. DOI: http://dx.doi.org/10.1016/j.agee.2014.03.017

Zhen W, Tao Z (2008) Computational study of the tangential type turbine flowmeter. Flow Measurement and Instrumentation 19(5):233-239. DOI: http://dx.doi.org/10.1016/j.flowmeasinst.2007.11.003 